\title{
A Decision Making Approach with Linguistic Weight and Unavoidable Incomparable Ranking
}

\author{
Yunxia Zhang ${ }^{1}$, Degen Huang ${ }^{1}$, Wei Gao ${ }^{2, *}$, Vassilis G. Kaburlasos ${ }^{3}$ \\ ${ }^{1}$ School of Computer Science and Technology, Dalian University of Technology, Dalian, 116081, China \\ ${ }^{2}$ School of Computer and Information Technology, Liaoning Normal University, Dalian, 116024, China \\ ${ }^{3}$ HUMAIN-Lab, Department of Computer and Informatics Engineering, Kavala, 65404, Greece
}

\section{ARTICLE INFO}

Article History

Received 27 Jun 2019

Accepted 20 Sep 2019

\section{Keywords}

Linguistic lattice implication algebra Linguistic-real valuation function

Incomparable ranking

Linguistic decision making

\begin{abstract}
In order to deal with the decision making problem including some linguistic values uncertainty information, we propose an approach for decision making with linguistic weighted and unavoidable incomparable ranking based on Linguistic-valued lattice implication algebra (LV-LIA). The properties of binary operations $\otimes$ and $\oplus$ are discussed in LV-LIA, and used to handle importance degree of the attributes expressed by linguistic values. We define a linguistic-real valuation function which is a positive valuation function and a linguistic-real metric distance implied by the linguistic-real valuation function is introduced, to process incomparable linguistic values in the results which need further procedure to make a certain decision. Illustrating examples show the effectiveness of the proposed approach which can rank the incomparable elements elastic.
\end{abstract}

(c) 2019 The Authors. Published by Atlantis Press SARL.

This is an open access article distributed under the CC BY-NC 4.0 license (http://creativecommons.org/licenses/by-nc/4.0/).

\section{INTRODUCTION}

In terms of common sense, people use linguistic terms in nature language for evaluating, reasoning and making decision, rather than crisp numbers. Hence, collection with qualitative information is always got, for example, object-attribute assessment for a car may be "very cheap" in price, "slightly comfortable" in comfort, "somewhat dangerous" in safety. To handle the qualitative information, many linguistic terms models have been proposed based on computing with words (CWW) [1,2], such as fuzzy set theory [3-5], symbolic approaches [6,7] and linguistic truth-valued mode in lattice order $[8,9]$.

Fuzzy set theory was proposed by Zadeh in 1965 using a membership function to model the uncertain information [5]. But it is difficult to find appropriate membership function when we confronted with the circumstances where various concepts are given in various contexts. Type- 2 fuzzy set is the extension of ordinary fuzzy set based on the theory of computing with words (CWW) [2]. Unlike a type-1 fuzzy set where the membership grade is a crisp number in $[0,1]$, the membership grade of Type-2 fuzzy set was extended to an ordinary fuzzy set [2-4]. Type-2 fuzzy set plays a role in wider applications and processes the uncertain information more flexibility [10-12].

Symbolic approaches use linguistic symbols to represent linguistic information directly without the numerical approximation required by fuzzy set based methods, and aggregate or compute on the indexes of these symbols to obtain the final result $[13,14]$.

\footnotetext{
*Corresponding author. Email: gwlnnu@163.com
}

Symbolic approach has performed well in decision making problems especially semantic interpretation of linguistic terms in nature language $[15,16]$. But there exists some loss of information when the results come out from the initial expression domain. Francisco Herrera and Luis Martínez proposed a 2-tuple model which are composed by a linguistic term and a numeric value assessed in $[-0.5$, $0.5)[17,18]$. The 2 -tuple model is widely used in many real problems for that it can avoid information losing in linguistic information processing and many aggregation operators of 2-tuple model were provided [19-22].

The conventional symbolic approach for linguistic value uses a linear order structure. However, in the natural language, some linguistic values are incomparable, for example, "Exactly True" and "Somewhat False." Obviously, it is difficult to describe the incomparable values utilizing a linear order structure. Lattice implication algebra (LIA) structure can imitate the uncertain and both comparable and incomparable characteristic [7]. Many researchers have studied in varied direction of LIA $[23,24]$. Jun Liu et al. have proposed an axiomatizable lattice ordered qualitative linguistic truth-valued logic system, which is a foundation for establishing formal linguistic truth-valued logic [25]. Xingxing He et al. have unified method for finding the structure of $k$-IESF in linguistic truth-valued lattice-valued propositional logic which provided a theoretical foundations and algorithms for $\alpha$-resolution automated reasoning [26]. Yang $\mathrm{Xu}$ et al. have extended the binary $\alpha$ resolution to multiary $\alpha$-resolution in lattice-valued propositional logic $L P(X)$ and lattice-valued first-order logic $L F(X)$, obtained a result that multiary $\alpha$-resolution principle in $L F(X)$ can be equivalently transformed into that in $L P(X)$ [27]. Yi Liu and Vassilis 
G. Kaburlasos et al. have introduced a LIA with implication values in a complete lattice of intervals on the real number axis which followed a capacity to optimize [28]. Li Zou proposed a linguisticvalued knowledge representation mode and approximated reasoning approach with linguistic-valued credibility factors [29].

All the above researches provided the feasibility of decision making with linguistic values based on linguistic-valued lattice implication algebra (LV-LIA). Besides object-attribute assessment, the importance of the attributes is often expressed using linguistic terms. However, the linguistic weights are always transformed to numbers or values on a linear order structure in a decision making problem [30]. This paper is aiming at decision making problems not only with the linguistic evaluation set but also the linguistic important degree, i.e., linguistic weight. We will propose a decision making model based on LV-LIA which has a flexible linguistic weighted method.

LV-LIA can express both comparable and incomparable linguistic information, which is consistent with nature language characteristic. In decision making there often exist some incomparable linguistic-valued decision making results. The positive valuation function (PVF) which implies a metric distance as well as an inclusion measure function can mapping a lattice to a real set [31]. We define a linguistic-real valuation function and get a rank with incomparable linguistic values through the linguistic-real metric distance (LRMD) elastic according to the individual preference degree.

Based on the aforementioned academic ideas, we will introduce a decision making approach based on 18-element LV-LIA.

The rest of paper is organized as follows: In section 2, we briefly review the concepts of LIA and LV-LIA. In section 3, we discuss the properties of the operations $\otimes$ and $\oplus$ of LV-LIA, and propose a decision making model with linguistic weighted method. In section 4 , we introduce a linguistic-real valuation function implied a metric distance to rank the incomparable decision making results. In section 5 , some conclusions are summarized.

\section{LINGUISTIC-VALUED LATTICE IMPLICATION ALGEBRA}

We briefly review some concepts of linguistic truth-valued LIA. We refer to the related Ref. [7].

Definition 1. [7] Let ( $L, \vee, \wedge, O, I)$ be a bounded lattice with universal boundaries $O$ (the least element) and I (the greatest element) respectively, and "' " be an order-reversing involution. For any $x, y, z \in L$, if mapping $\rightarrow: L \times L \rightarrow L$ satisfies:

$$
\begin{aligned}
& (I 1): x \rightarrow(y \rightarrow z)=y \rightarrow(x \rightarrow z) ; \\
& (I 2): x \rightarrow x=I ; \\
& (I 3): x \rightarrow y=y^{\prime} \rightarrow x^{\prime} ; \\
& (I 4): x \rightarrow y=y \rightarrow x=I \text { implies } x=y ; \\
& (I 5):(x \rightarrow y) \rightarrow y=(y \rightarrow x) \rightarrow x ; \\
& (I 6):(x \vee y) \rightarrow z=(x \rightarrow z) \wedge(y \rightarrow z) ; \\
& (I 7):(x \wedge y) \rightarrow z=(x \rightarrow z) \vee(y \rightarrow z) .
\end{aligned}
$$

Then $(L, \vee, \wedge, ', \rightarrow, O, I)$ is an LIA.
Definition 2. [7] Let $L_{n+1}=\left\{d_{0}, d_{1}, \cdots, d_{n}\right\}, d_{0}<d_{2}<\cdots<d_{n}$, $L_{2}=\left\{b_{1}, b_{2}\right\}, b_{1}<b_{2},\left(L_{n+1}, \wedge_{\left(L_{n+1}\right)}, \wedge_{\left(L_{n+1}\right)},{ }^{\prime}\left(L_{n+1}\right), \rightarrow\left(L_{n+1}\right)\right.$, $\left.d_{0}, d_{n}\right)$ and $\left(L_{2}, \vee_{\left(L_{2}\right)}, \wedge_{\left(L_{2}\right)},{ }_{\left(L_{2}\right)}, \rightarrow_{\left(L_{2}\right)}, b_{1}, b_{2}\right)$ be Lukasiewicz implication algebra. For any $\left(d_{i}, b_{j}\right),\left(d_{k}, b_{m}\right) \in L_{n+1} \times L_{2}$, if

$$
\begin{aligned}
\left(d_{i}, b_{j}\right) \vee\left(d_{k}, b_{m}\right) & =\left(d_{i} \vee_{\left(L_{n}\right)} d_{k}, b_{j} \vee_{\left(L_{2}\right)} b_{m}\right), \\
\left(d_{i}, b_{j}\right) \wedge\left(d_{k}, b_{m}\right) & =\left(d_{i} \wedge{\left(L_{n}\right)}_{k} d_{k}, b_{j} \wedge{\left(L_{2}\right)}_{m} b_{m}\right), \\
\left(d_{i}, b_{j}\right)^{\prime} & =\left(d_{i}^{\prime\left(L_{n}\right)}, b_{j}^{\prime\left(L_{2}\right)}\right), \\
\left(d_{i}, b_{j}\right) \rightarrow\left(d_{k}, b_{m}\right) & =\left(d_{i} \rightarrow{ }_{\left(L_{n}\right)} d_{k}, b_{j} \rightarrow\left(L_{2}\right)\right.
\end{aligned}
$$

then $\left(L_{n+1} \times L_{2}, \vee, \wedge,{ }^{\prime}, \rightarrow,\left(d_{1}, b_{1}\right),\left(d_{n}, b_{2}\right)\right)$ is a LIA, denote as $\mathcal{L}_{n} \times \mathcal{L}_{2}$.

Definition 3. [7] Let $A D_{n+1}=\left\{h_{0}, h_{1}, \cdots, h_{n}\right\}$ be a set of $n$ hedge operators and $h_{0}<h_{1}<\cdots<h_{n}, M T=\{f, t\}$ be "false $(f)$ " and "true $(t)$ ", denote $f<t$ and $L_{V((n+1) \times 2)}=A D_{n+1} \times M T$. Define the mapping $g: L_{V((n+1) \times 2)} \rightarrow \mathcal{L}_{n+1} \times \mathcal{L}_{2}$ as follows.

$$
g\left(\left(h_{i}, m t\right)\right)=\left\{\begin{array}{l}
\left(d_{i}^{\prime}, b_{1}\right), m t=f, \\
\left(d_{i}, b_{2}\right), m t=t .
\end{array}\right.
$$

Then $g$ is bijection. Its inverse mapping is $g^{-1}$. For any $x, y \in$ $L_{V((n+1) \times 2)}$, define

$$
\begin{aligned}
x \vee y & =g^{-1}(g(x) \vee g(y)), \\
x \wedge y & =g^{-1}(g(x) \wedge g(y)), \\
x^{\prime} & =g^{-1}\left(g(x)^{\prime}\right), \\
x \rightarrow y & =g^{-1}(g(x) \rightarrow g(y)) .
\end{aligned}
$$

Then $\mathcal{L}_{V((n+1) \times 2)}=\left(L_{V((n+1) \times 2)}, \vee, \wedge,{ }^{\prime}, \rightarrow,\left(h_{n}, f\right),\left(h_{n}, t\right)\right)$ is called linguistic truth-valued LIA from $A D_{n+1}$ and $M T$ (Figure 1). $g$ is an isomorphic mapping from $\left(L_{V((n+1) \times 2)}, \vee, \wedge,{ }^{\prime}, \rightarrow,\left(h_{n}, f\right),\left(h_{n}, t\right)\right)$ to $\mathcal{L}_{n+1} \times \mathcal{L}_{2}$.

The operation " $\rightarrow$ " is

$$
\left\{\begin{array}{l}
\left(h_{i}, c_{2}\right) \rightarrow\left(h_{j}, c_{1}\right)=\left(h_{\max \{0, i+j-n\}}, c_{1}\right), \\
\left(h_{i}, c_{1}\right) \rightarrow\left(h_{j}, c_{2}\right)=\left(h_{\min \{n, i+j\}}, c_{2}\right), \\
\left(h_{i}, c_{2}\right) \rightarrow\left(h_{j}, c_{2}\right)=\left(h_{\min \{n, n-i+j\}}, c_{2}\right), \\
\left(h_{i}, c_{1}\right) \rightarrow\left(h_{j}, c_{1}\right)=\left(h_{\min \{n, n-j+i\}}, c_{2}\right) .
\end{array}\right.
$$

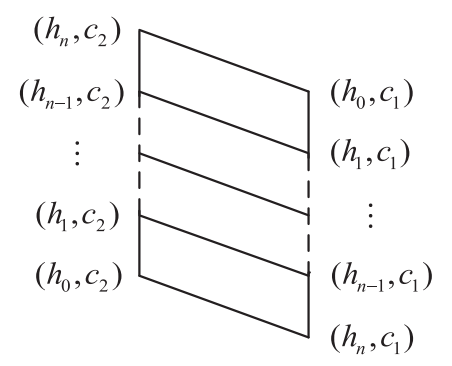

Figure 1 The Hasse diagram of $\mathcal{L}_{V((n+1) \times 2)}$. 
Note that $n$ should be an even number when we construct the $\mathcal{L}_{V((n+1) \times 2)}$.

\section{THE DECISION MAKING APPROACH WITH LINGUISTIC WEIGHTED BASED ON LV-LIA}

In a multi-attributes decision making problem, sometimes attribute importance is expressed with linguistic terms. We explore a linguistic weighted method expressing these linguistic weights with a linguistic lattice structure based on LV-LIA and apply it into decision making with linguistic weight in this section.

\subsection{The Operations in LV-LIA}

In a LIA $L$, there exist two binary operations $\otimes$ and $\oplus$ as follows [7].

For any $x, y \in L$,

$$
\begin{gathered}
x \otimes y=\left(x \rightarrow y^{\prime}\right)^{\prime}, \\
x \oplus y=x^{\prime} \rightarrow y .
\end{gathered}
$$

Similarly, we extend two binary operations $\otimes$ and $\oplus$ into LV-LIA.

Definition 4. For any $\left(h_{i}, c_{k}\right),\left(h_{j}, c_{l}\right) \in \mathcal{L}_{V((n+1) \times 2)}$, the binary operation $s \otimes$ and $\oplus$ are defined as follows,

$$
\begin{aligned}
& \left(h_{i}, c_{k}\right) \otimes\left(h_{j}, c_{l}\right)=\left(\left(h_{i}, c_{k}\right) \rightarrow\left(h_{j}, c_{l}\right)^{\prime}\right)^{\prime}, \\
& \left(h_{i}, c_{k}\right) \oplus\left(h_{j}, c_{l}\right)=\left(h_{i}, c_{k}\right)^{\prime} \rightarrow\left(h_{j}, c_{l}\right) .
\end{aligned}
$$

According to Eqs. (4) and (7), an equal definition is obtained.

For operation $\otimes$, there exist

$$
\left\{\begin{array}{l}
\left(h_{i}, c_{2}\right) \otimes\left(h_{j}, c_{1}\right)=\left(h_{\min (n, n-i+j)}, c_{1}\right), \\
\left(h_{i}, c_{1}\right) \otimes\left(h_{j}, c_{2}\right)=\left(h_{\min (n, n-j+i)}, c_{1}\right), \\
\left(h_{i}, c_{2}\right) \otimes\left(h_{j}, c_{2}\right)=\left(h_{\max (0, j+i-n)}, c_{2}\right), \\
\left(h_{i}, c_{1}\right) \otimes\left(h_{j}, c_{1}\right)=\left(h_{\min (n, i+j)}, c_{1}\right) .
\end{array}\right.
$$

And for operation $\oplus$, there exist

$$
\left\{\begin{array}{l}
\left(h_{i}, c_{2}\right) \oplus\left(h_{j}, c_{1}\right)=\left(h_{\min (n, n-j+i)}, c_{2}\right), \\
\left(h_{i}, c_{1}\right) \oplus\left(h_{j}, c_{2}\right)=\left(h_{\min (n, n-i+j)}, c_{2}\right), \\
\left(h_{i}, c_{2}\right) \oplus\left(h_{j}, c_{2}\right)=\left(h_{\min (n, i+j)}, c_{2}\right), \\
\left(h_{i}, c_{1}\right) \oplus\left(h_{j}, c_{1}\right)=\left(h_{\max (0, i+j-n)}, c_{1}\right) .
\end{array}\right.
$$

As $\mathcal{L}_{V((n+1) \times 2)}$ is a LIA, for any $\left(h_{i}, c_{k}\right),\left(h_{j}, c_{l}\right),\left(h_{s}, c_{t}\right) \in \mathcal{L}_{V((n+1) \times 2)}$ $\in \mathcal{L}_{V((n+1) \times 2)}$, we get the following properties,

i. $\quad\left(h_{i}, c_{k}\right) \otimes\left(h_{j}, c_{l}\right)=\left(h_{j}, c_{l}\right) \otimes\left(h_{i}, c_{k}\right)$, $\left(h_{i}, c_{k}\right) \oplus\left(h_{j}, c_{l}\right)=\left(h_{j}, c_{l}\right) \oplus\left(h_{i}, c_{k}\right)$.

ii. $\left(h_{i}, c_{k}\right) \otimes\left(h_{n}, c_{2}\right)=\left(h_{i}, c_{k}\right)$, $\left(h_{i}, c_{k}\right) \otimes\left(h_{n}, c_{1}\right)=\left(h_{i}, c_{k}\right)$, $\left(h_{i}, c_{k}\right) \oplus\left(h_{n}, c_{2}\right)=\left(h_{n}, c_{2}\right)$, $\left(h_{i}, c_{k}\right) \oplus\left(h_{n}, c_{1}\right)=\left(h_{i}, c_{k}\right)$. iii. $\quad\left(h_{i}, c_{k}\right) \otimes\left(h_{n}, c_{2}\right) \otimes\left(h_{s}, c_{t}\right)=\left(h_{i}, c_{k}\right) \otimes\left(\left(h_{n}, c_{2}\right) \otimes\left(h_{s}, c_{t}\right)\right)$, $\left(h_{i}, c_{k}\right) \otimes\left(h_{n}, c_{2}\right) \otimes\left(h_{s}, c_{t}\right)=\left(h_{i}, c_{k}\right) \otimes\left(\left(h_{n}, c_{2}\right) \otimes\left(h_{s}, c_{t}\right)\right)$.

Some other special properties of the operations $\otimes$ and $\oplus$ in LV-LIA are listed as follows.

Theorem 1. For any $\left(h_{i}, c_{k}\right),\left(h_{j}, c_{l}\right) \in \mathcal{L}_{V((n+1) \times 2)}$,

$$
\begin{aligned}
& \left(h_{i}, c_{k}\right) \otimes\left(h_{j}, c_{l}\right) \leq\left(h_{i}, c_{k}\right), \\
& \left(h_{i}, c_{k}\right) \otimes\left(h_{j}, c_{l}\right) \leq\left(h_{j}, c_{l}\right), \\
& \left(h_{i}, c_{k}\right) \oplus\left(h_{j}, c_{l}\right) \geq\left(h_{i}, c_{k}\right), \\
& \left(h_{i}, c_{k}\right) \oplus\left(h_{j}, c_{l}\right) \geq\left(h_{j}, c_{l}\right) .
\end{aligned}
$$

Proof. We prove it from four situations.

$\begin{aligned} & \text { i. } c_{k}=c_{2} \text { and } c_{l}=c_{1} ; \\ & \text { ii. } c_{k}=c_{1} \text { and } c_{l}=c_{2} ; \\ & \text { iii. } c_{k}=c_{2} \text { and } c_{l}=c_{2} ; \\ & \text { iv. } \quad c_{k}=c_{1} \text { and } c_{l}=c_{1} .\end{aligned}$

Without loss of generality, we only prove situation at that $c_{k}=c_{2}$ and $c_{l}=c_{1}$. The other situations can be proved similarly.

From Eq. (8), we know that

$\left(h_{i}, c_{2}\right) \otimes\left(h_{j}, c_{1}\right)=\left(h_{\min (n, n-i+j)}, c_{1}\right)$.

$\left(h_{\min (n, n-i+j)}, c_{1}\right) \leq\left(h_{n-i}, c_{1}\right)<\left(h_{i}, c_{2}\right)$, for $n-i+j \geq n-i$.

$\left(h_{\min (n, n-i+j)}, c_{1}\right) \leq\left(h_{j}, c_{1}\right)$, for $n-i+j \geq j$.

Hence, $\left(h_{i}, c_{k}\right) \otimes\left(h_{j}, c_{l}\right) \leq\left(h_{j}, c_{l}\right)$.

From Eq. (9), we know that

$\left(h_{i}, c_{2}\right) \oplus\left(h_{j}, c_{1}\right)=\left(h_{\min (n, n-j+i)}, c_{2}\right)$.

$\left(h_{\min (n, n-j+i)}, c_{2}\right) \geq\left(h_{i}, c_{2}\right)$, as $n-j+i \geq i$.

$\left(h_{\min (n, n-j+i)}, c_{2}\right) \geq\left(h_{n-j}, c_{2}\right)>\left(h_{j}, c_{1}\right)$, for $n-j+i \geq n-j$.

Hence, $\left(h_{i}, c_{k}\right) \oplus\left(h_{j}, c_{l}\right) \geq\left(h_{j}, c_{l}\right)$.

It also can be proved in the other situations that

$$
\begin{aligned}
& \left(h_{i}, c_{k}\right) \otimes\left(h_{j}, c_{l}\right) \leq\left(h_{j}, c_{l}\right), \\
& \left(h_{i}, c_{k}\right) \oplus\left(h_{j}, c_{l}\right) \geq\left(h_{j}, c_{l}\right) .
\end{aligned}
$$

From the properties of the operations $\otimes$ and $\oplus$ in LV-LIA,

$$
\begin{aligned}
& \left(h_{i}, c_{k}\right) \otimes\left(h_{j}, c_{l}\right) \leq\left(h_{i}, c_{k}\right) . \\
& \left(h_{i}, c_{k}\right) \oplus\left(h_{j}, c_{l}\right) \geq\left(h_{i}, c_{k}\right) .
\end{aligned}
$$

Theorem 2. For any $\left(h_{i}, c_{k}\right),\left(h_{j}, c_{l}\right),\left(h_{s}, c_{t}\right), \in \mathcal{L}_{V((n+1) \times 2)}$, if $\left(h_{i}, c_{k}\right) \leq\left(h_{j}, c_{l}\right)$, then

$$
\begin{aligned}
& \left(h_{i}, c_{k}\right) \otimes\left(h_{s}, c_{t}\right) \leq\left(h_{j}, c_{l}\right) \otimes\left(h_{s}, c_{t}\right), \\
& \left(h_{i}, c_{k}\right) \oplus\left(h_{s}, c_{t}\right) \leq\left(h_{j}, c_{l}\right) \oplus\left(h_{s}, c_{t}\right) .
\end{aligned}
$$


It can be proved from the Eqs. (8) and (9) respectively.

According to the properties of the operations $\otimes$ and $\oplus$ in LV-LIA, we obtain

$$
\begin{aligned}
& \left(h_{s}, c_{t}\right) \otimes\left(h_{i}, c_{k}\right) \leq\left(h_{s}, c_{t}\right) \otimes\left(h_{j}, c_{l}\right), \\
& \left(h_{s}, c_{t}\right) \oplus\left(h_{i}, c_{k}\right) \leq\left(h_{s}, c_{t}\right) \oplus\left(h_{j}, c_{l}\right) .
\end{aligned}
$$

Suppose that $x_{i}, x_{j}$ are two assessments with respect to the $i$ th and the $j$ th attribute of an alternative expressed by linguistic values on LV-LIA and $\omega_{i}, \omega_{j}$ are two linguistic weights on LV-LIA. Then according to the Theorem 1 , we have

$$
x_{i} \otimes \omega_{i}<x_{i}
$$

According to the Theorem 2, if $x_{i} \leq x_{j}$ or $\omega_{i} \leq \omega_{j}$, we have

$$
\begin{aligned}
& \omega_{i} \otimes x_{i} \leq \omega_{j} \otimes x_{i}, \\
& \omega_{i} \otimes x_{i} \leq \omega_{i} \otimes x_{j} .
\end{aligned}
$$

That shows that when the assessments of alternatives are the same, more important the attribute is, higher evaluation the alternative achieves. Accordingly, when the weights of attributes are the same, larger the assessment of alternative is, higher evaluation the alternative achieves.

\subsection{The Decision Making Approach Based on 18LV-LIA}

In generally, linguistic terms with linguistic hedges can be seen as linguistic modifiers and prime terms. In the following, we divide the linguistic terms into nine linguistic hedges (modifiers) applying to two prime terms. The linguistic modifiers of LV-LIA are \{Slightly (Sl for short), Somewhat (So), Rather (Ra), Almost (Al), Exactly (Ex), Quite $(\mathrm{Qu})$, Very $(\mathrm{Ve})$, Highly $(\mathrm{Hi})$, Absolutely $(\mathrm{Ab})\}$ with the semantic ordering relationship $S l<S o<R a<A l<E x<Q u<V e<H i<$ $A b$, i.e., the hedge set is $A D_{9}=\left\{h_{0}=S l, h_{1}=S o, h_{2}=R a, h_{3}=\right.$ $\left.A l, h_{4}=E x, h_{5}=Q u, h_{6}=V e, h_{7}=H i, h_{8}=A b\right\}$. The prime terms are $\{$ Dissatisfied (Ds for short), Satisfied $(\mathrm{Sa})\}$ representing a pair opposite meta vague concept with $D s<S a$, i.e., the prime term set $M T=\left\{c_{1}=D s, c_{2}=S a\right\}$. Applying the linguistic modifiers of $A D_{9}$ to the prime terms $M T$, we obtain a partially ordered lattice $\mathcal{L}_{V(9 \times 2)}=\left(L_{V(9 \times 2)}, \vee, \wedge,{ }^{\prime}, \rightarrow,\left(h_{8}, c_{2}\right),\left(h_{8}, c_{1}\right)\right)$ called 18element linguistic-valued lattice implication algebra (18LV-LIA) (Figure 2) [32].

A decision making model is constructed based on 18LV-LIA. Weights of the attributes are expressed with linguistic terms on LVLIA. The operation $\otimes$ can be used to calculate the linguistic weight. The attribute aggregation can be done according to the aggregation rules which can be set flexibly based on the actual cases.

There are some aggregation function about the logical relation "or" and "and".

For relation " $\left(h_{i}, c_{k}\right)$ and $\left(h_{j}, c_{l}\right)$ " can be aggregated as,

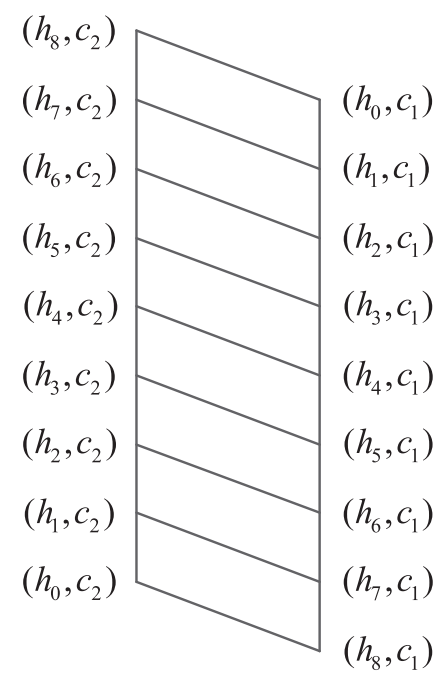

Figure 2 The Hasse diagram of $\mathcal{L}_{V(9 \times 2)}$.

i. $\quad F_{\text {and }}\left(\left(h_{i}, c_{k}\right),\left(h_{j}, c_{l}\right)\right)=$

$$
\left\{\begin{array}{l}
\left(h_{\left[\frac{i+j}{2}\right]}, c_{l}\right), \text { if } k=l \\
\left(h_{\left[\frac{8+i \cdot \operatorname{sgn}(k-1.5)+j \cdot \operatorname{sgn}(l-1.5)}{2}\right]}, c_{2}\right), \text { if } k \neq l
\end{array},\right.
$$

where $\operatorname{sgn}(\cdot)$ is the sign function, the maximum subscript of the hedges in 18LV-LIA is 8 , and 1.5 is the median point of the subscript of prime term, in fact, it can be any point in interval $(1,2)$.

ii. $F_{\text {and }}\left(\left(h_{i}, c_{k}\right),\left(h_{j}, c_{l}\right)\right)=\left(h_{i}, c_{k}\right) \wedge\left(h_{j}, c_{l}\right)$.

For relation “ $\left(h_{i}, c_{k}\right)$ or $\left(h_{j}, c_{l}\right)$ ” can be aggregated as,

iii. $\quad F_{\text {or }}\left(\left(h_{i}, c_{k}\right),\left(h_{j}, c_{l}\right)\right)=\left\{\begin{array}{l}\left(h_{u}, c_{2}\right), \text { if } k \| l \\ \max \left(\left(h_{i}, c_{k}\right),\left(h_{j}, c_{l}\right)\right) \text {, others }\end{array}\right.$

where $u=\max (n, 8+i \cdot \operatorname{sgn}(k-1.5)+j \cdot \operatorname{sgn}(l-1.5))$, and the parameters means the same with parameters in Eq. (10).

iv. $F_{\text {or }}\left(\left(h_{i}, c_{k}\right),\left(h_{j}, c_{l}\right)\right)=\left(h_{i}, c_{k}\right) \vee\left(h_{j}, c_{l}\right)$.

They all satisfy the associative law and commutative law.

A linguistic multi-attribute decision making problem consists of a finite and non-empty alternative set $A=\left\{A_{1}, A_{2}, \cdots, A_{k}\right\}$, where each alternative is defined by means of a finite set of attribute, $C=$ $\left\{C_{1}, C_{2}, \cdots, C_{m}\right\}$ which is assessed using linguistic expressions, and the corresponding weight set for attributes is $W=\left(\omega_{1}, \omega_{2}, \cdots, \omega_{m}\right)$.

The decision making approach based on 18LV-LIA consists mainly of the flowing steps.

Step 1. Linguistic assessment matrix and linguistic weight transforming. The linguistic assessment matrix is 


$$
E=\left(\begin{array}{llll}
a_{11} & a_{12} & \cdots & a_{1 m} \\
a_{21} & \ddots & & a_{2 m} \\
\vdots & & \ddots & \vdots \\
a_{N 1} & a_{N 2} & \cdots & a_{k m}
\end{array}\right)
$$

In the linguistic assessment matrix, $a_{i j} \in \mathcal{L}_{V(9 \times 2)}$ is the assessment about the attribute $C_{j}$ of alternative $A_{i}$.

The attribute weights given by the experts are the linguistic terms in $\mathcal{L}_{V(9 \times 2)}$ as

$$
W=\left\{\omega_{1}, \omega_{2}, \cdots, \omega_{m}\right\}
$$

In this step, the attribute assessment collection of alternatives is transformed to linguistic terms on $\mathcal{L}_{V(9 \times 2)}$.

Step 2. Weighted evaluation matrix Construction. Weighted evaluation matrix is constructed from Eq. (8).

$$
M=\left(\begin{array}{cccc}
b_{11} & b_{12} & \cdots & b_{1 m} \\
b_{21} & \ddots & & b_{2 m} \\
\vdots & & \ddots & \vdots \\
b_{N 1} & b_{N 2} & \cdots & b_{m N}
\end{array}\right)=E \otimes W
$$

where $b_{i j}=a_{i j} \otimes \omega_{j}$.

Step 3. Aggregation function setting and comprehensive evaluations aggregation.

The comprehensive evaluation

$$
b_{i}=F\left(b_{i 1}, b_{i 2}, \cdots, b_{i m}\right) \text {, }
$$

where $F(\cdot)$ is the aggregation function of the weighted evaluation.

Step 4. Decision making process. The comprehensive evaluations $b_{i}$ $(i=1,2, \cdots, N)$ are ranked with respect to each alternative according to Fig. 2.

Here are a few notes. The aggregation function is set as

$$
F\left(b_{i 1}, b_{i 2}, \cdots, b_{i m}\right)=F_{m-1}\left(\cdots F_{2}\left(F_{1}\left(b_{i 1}, b_{i 2}\right), b_{i 3}\right) \cdots, b_{i m}\right) \text {, }
$$

where $F_{k}(\cdot)$ is the aggregation operators of $b_{i k}$ and $b_{i, k-1}$ related to their logical relation, $b_{i}$ is the comprehensive evaluation of the $i$ th alternative. The function can be a logical operator, an arithmetical operator or even a hybrid one.

It is also noted that incomparable linguistic results are allowed.

\subsection{Examples Illustration}

Example 1. A teaching evaluation system with linguistic information.

To show how the proposed approach works, we give a teaching evaluation system which help decision makers evaluate the teacher's teaching quality. Suppose that the teaching quality depends on four attributes, responsibility, lesson preparation, professional proficiency and teaching efficiency. The attribute set is denoted as $C=\left\{C_{1}, C_{2}, C_{3}, C_{4}\right\}$. The alternative set is $A=\left\{A_{1}, A_{2}, A_{3}, A_{4}\right\}$ representing four teachers respectively.
Step 1. The assessment collection with respect to the attributes of four teachers about teaching quality is shown in Table 1. The linguistic terms are the linguistic values in $\mathcal{L}_{V(9 \times 2)}$. We get the initial assessment matrix.

$$
E=\left(\begin{array}{llll}
\left(h_{4}, c_{2}\right) & \left(h_{5}, c_{2}\right) & \left(h_{4}, c_{2}\right) & \left(h_{8}, c_{2}\right) \\
\left(h_{4}, c_{2}\right) & \left(h_{1}, c_{1}\right) & \left(h_{4}, c_{2}\right) & \left(h_{8}, c_{1}\right) \\
\left(h_{7}, c_{2}\right) & \left(h_{5}, c_{2}\right) & \left(h_{7}, c_{2}\right) & \left(h_{4}, c_{1}\right) \\
\left(h_{0}, c_{1}\right) & \left(h_{3}, c_{1}\right) & \left(h_{0}, c_{1}\right) & \left(h_{4}, c_{2}\right)
\end{array}\right) .
$$

$W_{1}, W_{2}$ and $W_{3}$ are three weight vectors.

$$
\begin{aligned}
& W_{1}=\left(\left(h_{8}, c_{2}\right),\left(h_{8}, c_{2}\right),\left(h_{8}, c_{2}\right),\left(h_{8}, c_{2}\right)\right), \\
& W_{2}=\left(\left(h_{6}, c_{1}\right),\left(h_{4}, c_{2}\right),\left(h_{6}, c_{2}\right),\left(h_{8}, c_{1}\right)\right), \\
& W_{3}=\left(\left(h_{8}, c_{1}\right),\left(h_{8}, c_{1}\right),\left(h_{8}, c_{1}\right),\left(h_{8}, c_{1}\right)\right) .
\end{aligned}
$$

$W_{1}$ mans that all of the attribute are equally important. $W_{2}$ mans that the attributes are with different importance. $W_{3}$ means that all of the attributes are not important at all, where the case is that unavailable attributes are collected.

Step 2. The weighted matrix are got utilizing the operation $\otimes$ according to Eq. (8).

$$
\begin{aligned}
& M_{1}=\left(\begin{array}{llll}
\left(h_{4}, c_{2}\right) & \left(h_{5}, c_{2}\right) & \left(h_{4}, c_{2}\right) & \left(h_{8}, c_{2}\right) \\
\left(h_{4}, c_{2}\right) & \left(h_{1}, c_{1}\right) & \left(h_{4}, c_{1}\right) & \left(h_{8}, c_{1}\right) \\
\left(h_{7}, c_{2}\right) & \left(h_{5}, c_{2}\right) & \left(h_{7}, c_{2}\right) & \left(h_{4}, c_{1}\right) \\
\left(h_{0}, c_{1}\right) & \left(h_{3}, c_{1}\right) & \left(h_{0}, c_{1}\right) & \left(h_{4}, c_{2}\right)
\end{array}\right), \\
& M_{2}=\left(\begin{array}{llll}
\left(h_{8}, c_{1}\right) & \left(h_{1}, c_{2}\right) & \left(h_{2}, c_{2}\right) & \left(h_{8}, c_{1}\right) \\
\left(h_{8}, c_{1}\right) & \left(h_{5}, c_{1}\right) & \left(h_{2}, c_{2}\right) & \left(h_{8}, c_{1}\right) \\
\left(h_{7}, c_{1}\right) & \left(h_{1}, c_{2}\right) & \left(h_{5}, c_{2}\right) & \left(h_{8}, c_{1}\right) \\
\left(h_{6}, c_{1}\right) & \left(h_{7}, c_{1}\right) & \left(h_{2}, c_{1}\right) & \left(h_{8}, c_{1}\right)
\end{array}\right),
\end{aligned}
$$

$$
M_{3}=\left(\begin{array}{llll}
\left(h_{8}, c_{1}\right) & \left(h_{8}, c_{1}\right) & \left(h_{8}, c_{1}\right) & \left(h_{8}, c_{1}\right) \\
\left(h_{8}, c_{1}\right) & \left(h_{8}, c_{1}\right) & \left(h_{8}, c_{1}\right) & \left(h_{8}, c_{1}\right) \\
\left(h_{8}, c_{1}\right) & \left(h_{8}, c_{1}\right) & \left(h_{8}, c_{1}\right) & \left(h_{8}, c_{1}\right) \\
\left(h_{8}, c_{1}\right) & \left(h_{8}, c_{1}\right) & \left(h_{8}, c_{1}\right) & \left(h_{8}, c_{1}\right)
\end{array}\right) .
$$

Step 3. Suppose there is facts that a teacher who is responsible or prepare lesson fully, and professional proficiency or teaching efficiency should be with high teaching quality. It is a rule, as a teacher,

IF (responsible or prepare lesson fully) and (professional proficiency or teaching efficiency) THEN (with high teaching quality).

The aggregation function for relation "or" is set as the logical operation Eq. (13). The aggregation function for relation "and" is set as the arithmetic operations Eq. (10). The weighted evaluations under $W_{2}$ are listed in the Table 2.

And by the aggregation rule, we get the assessments of four teachers with different attribute weights (Table 3 ).

Step 4: The results in Table 3 are ranked (Table 4).

Table 1 The assessment collection about quality of teaching.

\begin{tabular}{lcccc}
\hline & $\boldsymbol{C}_{\mathbf{1}}$ & $\boldsymbol{C}_{\mathbf{2}}$ & $\boldsymbol{C}_{\mathbf{3}}$ & $\boldsymbol{C}_{\mathbf{4}}$ \\
\hline$A_{\mathbf{1}}$ & $(E x, S a)$ & $(\mathrm{Qu}, S a)$ & $(E x, S a)$ & $(A b, S a)$ \\
$A_{2}$ & $(E x, S a)$ & $(S o, D s)$ & $(E x, S a)$ & $(A b, D s)$ \\
$A_{3}$ & $(H i, S a)$ & $(Q u, S a)$ & $(H i, S a)$ & $(E x, D s)$ \\
$A_{4}$ & $(S l, D s)$ & $(A l, D s)$ & $(S l, D s)$ & $(E x, S a)$ \\
\hline
\end{tabular}


Table 2 The weighted evaluations values under $W_{2}$.

\begin{tabular}{ccccc}
\hline & $\boldsymbol{A}_{\mathbf{1}}$ & $\boldsymbol{A}_{\mathbf{2}}$ & $\boldsymbol{A}_{\mathbf{3}}$ & $\boldsymbol{A}_{\mathbf{4}}$ \\
\hline$C_{1}$ & $\left(h_{8}, c_{1}\right)$ & $\left(h_{1}, c_{2}\right)$ & $\left(h_{2}, c_{2}\right)$ & $\left(h_{8}, c_{1}\right)$ \\
$C_{2}$ & $\left(h_{8}, c_{1}\right)$ & $\left(h_{5}, c_{1}\right)$ & $\left(h_{2}, c_{2}\right)$ & $\left(h_{8}, c_{1}\right)$ \\
$C_{3}$ & $\left(h_{7}, c_{1}\right)$ & $\left(h_{1}, c_{2}\right)$ & $\left(h_{5}, c_{2}\right)$ & $\left(h_{8}, c_{1}\right)$ \\
$C_{4}$ & $\left(h_{6}, c_{1}\right)$ & $\left(h_{7}, c_{1}\right)$ & $\left(h_{2}, c_{1}\right)$ & $\left(h_{8}, c_{1}\right)$ \\
\hline
\end{tabular}

Table 3 Comprehensive evaluations.

\begin{tabular}{ccccc}
\hline & $\boldsymbol{A}_{\mathbf{1}}$ & $\boldsymbol{A}_{\mathbf{2}}$ & $\boldsymbol{A}_{\mathbf{3}}$ & $\boldsymbol{A}_{\mathbf{4}}$ \\
\hline$W_{1}$ & $\left(h_{6}, c_{2}\right)$ & $\left(h_{5}, c_{2}\right)$ & $\left(h_{7}, c_{2}\right)$ & $\left(h_{8}, c_{2}\right)$ \\
$W_{2}$ & $\left(h_{1}, c_{2}\right)$ & $\left(h_{3}, c_{2}\right)$ & $\left(h_{3}, c_{2}\right)$ & $\left(h_{4}, c_{1}\right)$ \\
$W_{3}$ & $\left(h_{8}, c_{1}\right)$ & $\left(h_{8}, c_{1}\right)$ & $\left(h_{8}, c_{1}\right)$ & $\left(h_{8}, c_{1}\right)$ \\
Without weights & $\left(h_{6}, c_{2}\right)$ & $\left(h_{5}, c_{2}\right)$ & $\left(h_{7}, c_{2}\right)$ & $\left(h_{8}, c_{2}\right)$ \\
\hline
\end{tabular}

Table 4 The final results with different weights.

\begin{tabular}{ccc}
\hline$W_{1}$ & $W_{2}$ & $W_{3}$ \\
\hline$A_{4}>A_{3}>A_{1}>A_{2}$, & $A_{2}=A_{3}>A_{1}$, & $A_{1}=A_{2}=A_{3}=A_{4}$. \\
& $A_{1} \| A_{4}$, & \\
$A_{2} \| A_{4}$, & \\
$A_{3} \| A_{4}$. & \\
\hline
\end{tabular}

From Table 2, we can see that the four teachers get the same assessments in attribute $C_{1}$ and $C_{3}$ but they get different weighted evaluations because the weights of attribute $C_{1}$ and $C_{3}$ are different. In fact, the two weights has the same linguistic hedges but the different prime terms, that can't expressed utilizing a linear structure.

From Table 3, we can see that when all attributes are absolutely important, the results equal to the results without any weight. Therefore, the present method not considering weights is a special case of the proposed approach.

When the weights of attribute are different, the results will be changed. For example, Teacher $A_{2}$ get higher score under the weight $W_{2}$ than it under the weight $W_{1}$.

From the results, we can see that when we consider all attribute absolutely unimportant, i.e., the weight vector is $W_{3}$, the four teachers get the same and lowest evaluation. It means that we collected unavailable data.

From Table 4, there are incomparable values in the results. For example, there exists the relation for $W_{2}$ as follows (Figure 3),

It is reasonable for that the incomparable cases exist in reality because of the characteristic of the linguistic value in nature language.

Remark: In step 3, taking the teacher $A_{1}$ when the weight set is $W_{2}$ as an example, we show the aggregation process.

$$
\begin{aligned}
F & =F_{\text {and }}\left(F_{\text {or }}\left(\left(h_{8}, c_{1}\right),\left(h_{1}, c_{2}\right)\right), F_{\text {or }}\left(\left(h_{2}, c_{2}\right),\left(h_{8}, c_{1}\right)\right)\right) \\
& =F_{\text {and }}\left(\left(\left(h_{8}, c_{1}\right) \vee\left(h_{1}, c_{2}\right)\right),\left(\left(h_{2}, c_{2}\right) \vee\left(h_{8}, c_{1}\right)\right)\right) \\
& =\left(h_{\left.\left[\frac{1+2}{2}\right], c_{2}\right)}\right. \\
& =\left(h_{1}, c_{2}\right) .
\end{aligned}
$$

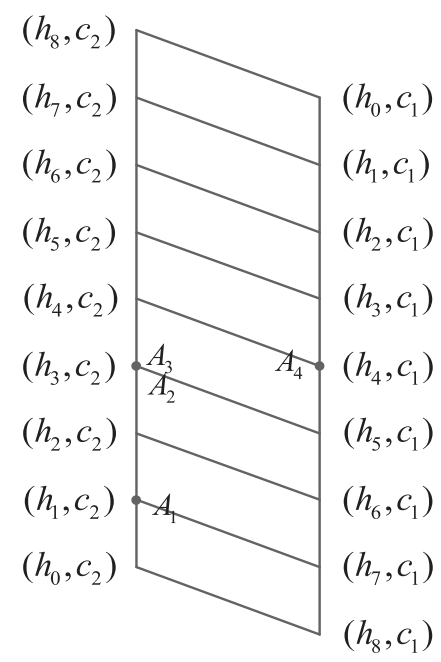

Figure 3 Relations of teachers on $\mathcal{L}_{V(9 \times 2)}$ under $W_{2}$.

Example 2. To illustrate the effectiveness of the method, an example of car evaluation in Ref. [30] is considered.

Suppose that there are three kinds of cars: BMW $\left(x_{1}\right)$, Hyundai $\left(x_{2}\right)$ and Passat $\left(x_{3}\right)$ are under evaluation according to four attributes: safety $\left(f_{1}\right)$, price $\left(f_{2}\right)$, comfort $\left(f_{3}\right)$ and fuel economy $\left(f_{4}\right)$. The linguistic judgments for evaluating the cars on $\mathcal{L}_{V(9 \times 2)}$ is as Table 5. The weights associated with the four criteria are supposed to be

$$
W_{1}=\left[\left(h_{8}, c_{2}\right),\left(h_{6}, c_{2}\right),\left(h_{3}, c_{2}\right),\left(h_{5}, c_{2}\right)\right] \text {, }
$$

or

$$
W_{2}=\left[\left(h_{8}, c_{1}\right),\left(h_{6}, c_{2}\right),\left(h_{3}, c_{1}\right),\left(h_{5}, c_{2}\right)\right]
$$

The comprehensive evaluations is as Table 6.

From Table 6, we can see that when the weights are positive prime terms, the two methods get the same results. But when the weights consist of negative prime terms, the method in Ref. [30] is hard to handle it.

In Ref. [30], Shuwei Chen et al. used the linguistic multi-criteria decision making approach based on logical reasoning. Our method is more widely in weight setting and more flexible in comprehensive way.

In Ref. [30], weights are from the positive prime terms only. But in this paper, weights can be positive prime terms or negative prime terms. And the aggregation function can be logical operators or arithmetic operators or hybrid operators in this paper. Our method can handle more widely cases. It is more flexible facing the complex problems in reality.

Table 5 Linguistic assessment about cars on $\mathcal{L}_{V(9 \times 2)}$.

\begin{tabular}{ccccc}
\hline & $\boldsymbol{f}_{\mathbf{1}}$ & $\boldsymbol{f}_{\mathbf{2}}$ & $\boldsymbol{f}_{\mathbf{3}}$ & $\boldsymbol{f}_{\mathbf{4}}$ \\
\hline$x_{1}$ & $\left(h_{6}, c_{2}\right)$ & $\left(h_{4}, c_{1}\right)$ & $\left(h_{7}, c_{2}\right)$ & $\left(h_{1}, c_{2}\right)$ \\
$x_{2}$ & $\left(h_{1}, c_{1}\right)$ & $\left(h_{5}, c_{2}\right)$ & $\left(h_{1}, c_{2}\right)$ & $\left(h_{4}, c_{2}\right)$ \\
$x_{3}$ & $\left(h_{6}, c_{2}\right)$ & $\left(h_{1}, c_{2}\right)$ & $\left(h_{5}, c_{2}\right)$ & $\left(h_{2}, c_{1}\right)$ \\
\hline
\end{tabular}


Table 6 The comprehensive evaluations from two methods.

\begin{tabular}{lccccccc}
\hline Weight & \multicolumn{4}{c}{$W_{1}$} & & \multicolumn{3}{c}{$W_{2}$} \\
\cline { 2 - 4 } \cline { 5 - 7 } Method & $x_{1}$ & $x_{2}$ & $x_{3}$ & & $x_{1}$ & $x_{2}$ & $x_{3}$ \\
\hline Our Method & $\left(h_{6}, c_{2}\right)$ & $\left(h_{7}, c_{2}\right)$ & $\left(h_{6}, c_{2}\right)$ & $\left(h_{4}, c_{2}\right)$ & $\left(h_{3}, c_{2}\right)$ & $\left(h_{3}, c_{2}\right)$ \\
Chen's method & $\left(h_{6}, c_{2}\right)$ & $\left(h_{7}, c_{2}\right)$ & $\left(h_{6}, c_{2}\right)$ & - & - & - \\
\hline
\end{tabular}

From the results in Table 4, incomparable linguistic values are existed rationally because of the inherent characteristic of linguistic value. However, a certain decision is demanded sometimes. Then some further works should be done in this case.

\section{RANKING METHOD FOR INCOMPARABLE LINGUISTIC VALUES}

From the Figure 2, we know that that $\left(h_{i}, c_{2}\right)$ and $\left(h_{n-1-i}, c_{1}\right)$ are incomparable. They can describe the incomparable linguistic terms in the nature language. The characteristic brings incomparable results. We utility a PVF to make a certain ranking when it is necessary. So this section is extension and supplement of the above.

\subsection{PVF for Linguistic-Value Lattice}

A valuation on a crisp lattice $L$ is a real-valued function $v: L \rightarrow R$ which satisfies $v(a)+v(b)=v(a \vee b)+v(a \wedge b), a, b \in L$. A valuation is called monotone if and only if $a \leq b$ in $L$ implies $v(a) \leq$ $v(b)$ and positive if and only if $a<b$ implies $v(a)<v(b)$ [11].

A PVF $v(\cdot)$ in a lattice $L$ implies a metric distance $d: L \times L \rightarrow R$ given by $d\left(x_{1}, x_{2}\right)=v\left(x_{1} \vee x_{2}\right)-v\left(x_{1} \wedge x_{2}\right)$ for $L$ [11].

Utilizing a PVF, a value on a lattice can be mapped to a real number which keeping the order of these comparable elements on a lattice. Aiming to handle the incomparable problem of the linguistic values on LV-LIA, a PVF is defined called linguistic-real positive-valuation function (LR-PVF) on LV-LIA.

Definition 5. Let $\mathcal{L}_{V((n+1) \times 2)}$ be a linguistic-value lattice, $\left(h_{i}, c_{k}\right)$ $\in \mathcal{L}_{V((n+1) \times 2)}(i=0,1,2 \cdots, n$ and $k=1,2)$. Let $\alpha, \beta \in[0,1]$ be two preference parameters which represent the preference degree to positive side and negative side respectively. The LR-PVF is defined as

$$
\begin{gathered}
v: \mathcal{L}_{V((n+1) \times 2)} \rightarrow R . \\
v\left(\left(h_{i}, c_{k}\right)\right)=\alpha \times(k-1)+\beta \times(n \times(2-k)+s(k) \times i),
\end{gathered}
$$

where $s(\cdot)$ is a function defined as

$$
s(k)= \begin{cases}-1, & k=1, \\ 1, & k=2,\end{cases}
$$

The preference parameters $\alpha, \beta$ make the LR-PVF be elastic by the individual performances. $(k-1),(2-k)$ and $s(k)$ are to distinguish the prime terms. An equal equipment is obtained by substituting $k$,

$$
v\left(\left(h_{i}, c_{k}\right)\right)= \begin{cases}\beta \times(n-i), & k=1, \\ \alpha+\beta \times i, & k=2 .\end{cases}
$$

Theorem 3. The linguistic-real valuation function $v: \mathcal{L}_{V((n+1) \times 2)} \rightarrow$ $R$ is a $P V F$.

It is proved in Appendix A.

Definition 6. LRMD which implied by PVF $v(\cdot)$ in LV-LIA is defined as

$$
\begin{gathered}
d l: \mathcal{L}_{V((n+1) \times 2)} \rightarrow R, \\
d l\left(x_{1}, x_{2}\right)=v\left(x_{1} \vee x_{2}\right)-v\left(x_{1} \wedge x_{2}\right) .
\end{gathered}
$$

Theorem 4. Suppose $\left(h_{i}, c_{k}\right),\left(h_{j}, c_{l}\right), \in \mathcal{L}_{V((n+1) \times 2)}$, the LRMD between $\left(h_{i}, c_{k}\right) \wedge\left(h_{j}, c_{l}\right)$ and $\left(h_{i}, c_{k}\right)$ is denoted as Dc $c_{1}$, the LRMD between $\left(h_{i}, c_{k}\right) \wedge\left(h_{j}, c_{l}\right)$ and $\left(h_{j}, c_{l}\right)$ is denoted as Dc $c_{2}$. Similarly, the LRMD between $\left(h_{i}, c_{k}\right) \vee\left(h_{j}, c_{l}\right)$ and $\left(h_{i}, c_{k}\right)$ is denoted as $D d_{1}$, the LRMD between $\left(h_{i}, c_{k}\right) \vee\left(h_{j}, c_{l}\right)$ and $\left(h_{j}, c_{l}\right)$ is denoted as $D d_{2}$.

If $D c_{1}<D c_{2}$ or $D d_{1}>D d_{2}$, then $\left(h_{i}, c_{k}\right)<\left(h_{j}, c_{l}\right)$.

Proof. $\quad D c_{1}=d l\left(\left(h_{i}, c_{k}\right),\left(\left(h_{i}, c_{k}\right) \wedge\left(h_{j}, c_{l}\right)\right)\right)$

$$
\begin{aligned}
= & v\left(\left(h_{i}, c_{k}\right) \vee\left(\left(h_{i}, c_{k}\right) \wedge\left(h_{j}, c_{l}\right)\right)\right) \\
& -v\left(\left(h_{i}, c_{k}\right) \wedge\left(\left(h_{i}, c_{k}\right) \wedge\left(h_{j}, c_{l}\right)\right)\right), \\
= & v\left(\left(h_{i}, c_{k}\right)\right)-v\left(\left(h_{i}, c_{k}\right) \wedge\left(h_{j}, c_{l}\right)\right) ;
\end{aligned}
$$

$$
\begin{aligned}
D c_{2}= & d l\left(\left(h_{j}, c_{l}\right),\left(\left(h_{i}, c_{k}\right) \wedge\left(h_{j}, c_{l}\right)\right)\right) \\
= & v\left(\left(h_{j}, c_{l}\right) \vee\left(\left(h_{i}, c_{k}\right) \wedge\left(h_{j}, c_{l}\right)\right)\right) \\
& -v\left(\left(h_{j}, c_{l}\right) \wedge\left(\left(h_{i}, c_{k}\right) \wedge\left(h_{j}, c_{l}\right)\right)\right), \\
= & v\left(\left(h_{j}, c_{l}\right)\right)-v\left(\left(h_{i}, c_{k}\right) \wedge\left(h_{j}, c_{l}\right)\right) .
\end{aligned}
$$

If $D c_{1}<D c_{2}$, i.e., $v\left(\left(h_{i}, c_{k}\right)\right)-v\left(\left(h_{i}, c_{k}\right) \wedge\left(h_{j}, c_{l}\right)\right)<v\left(\left(h_{j}, c_{l}\right)\right)-$ $v\left(\left(h_{i}, c_{k}\right) \wedge\left(h_{j}, c_{l}\right)\right)$. Then we know $v\left(\left(h_{i}, c_{k}\right)\right)<v\left(\left(h_{j}, c_{l}\right)\right)$. Since the LR-PVF $v(\cdot)$ is positive, we get $\left(h_{i}, c_{k}\right)<\left(h_{j}, c_{l}\right)$.

$$
\begin{aligned}
D d_{1}= & d l\left(\left(h_{i}, c_{k}\right),\left(\left(h_{i}, c_{k}\right) \vee\left(h_{j}, c_{l}\right)\right)\right) \\
= & v\left(\left(h_{i}, c_{k}\right) \vee\left(\left(h_{i}, c_{k}\right) \vee\left(h_{j}, c_{l}\right)\right)\right) \\
& -v\left(\left(h_{i}, c_{k}\right) \wedge\left(\left(h_{i}, c_{k}\right) \vee\left(h_{j}, c_{l}\right)\right)\right) \\
= & v\left(\left(h_{i}, c_{k}\right) \vee\left(h_{j}, c_{l}\right)\right)-v\left(\left(h_{i}, c_{k}\right)\right) . \\
D d_{2}= & d l\left(\left(h_{j}, c_{l}\right),\left(\left(h_{i}, c_{k}\right) \vee\left(h_{j}, c_{l}\right)\right)\right) \\
= & v\left(\left(h_{j}, c_{l}\right) \vee\left(\left(h_{i}, c_{k}\right) \vee\left(h_{j}, c_{l}\right)\right)\right) \\
& -v\left(\left(h_{j}, c_{l}\right) \wedge\left(\left(h_{i}, c_{k}\right) \vee\left(h_{j}, c_{l}\right)\right)\right) \\
= & v\left(\left(h_{i}, c_{k}\right) \vee\left(h_{j}, c_{l}\right)\right)-v\left(\left(h_{j}, c_{l}\right)\right) .
\end{aligned}
$$

If $D d_{1}>D d_{2}$, i.e., $v\left(\left(h_{i}, c_{k}\right) \vee\left(h_{j}, c_{l}\right)\right)-v\left(\left(h_{i}, c_{k}\right)\right)>$ $v\left(\left(h_{i}, c_{k}\right) \vee\left(h_{j}, c_{l}\right)\right)-v\left(\left(h_{j}, c_{l}\right)\right)$. Then we know $v\left(\left(h_{i}, c_{k}\right)\right)<$ $v\left(\left(h_{j}, c_{l}\right)\right)$. Since the LR-PVF $v(\cdot)$ is positive, we get $\left(h_{i}, c_{k}\right)<$ $\left(h_{j}, c_{l}\right)$.

Definition 7. Let $\left(h_{i}, c_{k}\right),\left(h_{j}, c_{l}\right) \in \mathcal{L}_{V((n+1) \times 2)}$, the LRMD between $\left(h_{i}, c_{k}\right) \wedge\left(h_{j}, c_{l}\right)$ and $\left(h_{i}, c_{k}\right)$ is denoted as $D c_{1}$ and the LRMD between $\left(h_{i}, c_{k}\right) \wedge\left(h_{j}, c_{l}\right)$ and $\left(h_{j}, c_{l}\right)$ is denoted as Dc $c_{2}$. Similarly, the LRMD between $\left(h_{i}, c_{k}\right) \vee\left(h_{j}, c_{l}\right)$ and $\left(h_{i}, c_{k}\right)$ is denoted as $D d_{1}$ and the LRMD between $\left(h_{i}, c_{k}\right) \vee\left(h_{j}, c_{l}\right)$ and $\left(h_{j}, c_{l}\right)$ is denoted as $D d_{2}$.

If $D c_{1}<D c_{2}$ or $D d_{1}>D d_{2}$, then we say $\left(h_{i}, c_{k}\right)$ is ranked after $\left(h_{j}, c_{l}\right)$, denoted as $\left(h_{i}, c_{k}\right)<\left(h_{j}, c_{l}\right)$.

It is obvious that if $\left(h_{i}, c_{k}\right)<\left(h_{j}, c_{l}\right)$, then $\left(h_{i}, c_{k}\right) \stackrel{\ddot{<}}{<}\left(h_{j}, c_{l}\right)$. 


\subsection{The Ranking Method Base on Linguistic-Real Valuation Function}

Individual preference to the positive side and the negative side is different. We adjust the preference parameters in linguistic-real valuation function according to individual's preference for incomparable ranking.

Suppose $\left(h_{i}, c_{k}\right),\left(h_{j}, c_{l}\right) \in \mathcal{L}_{V((n+1) \times 2)}$ are two incomparable linguistic values in the decision making problems, we rank them utilizing LRMD from Theorem 4.

The flowchart of the developing ranking process by considering the incomparable values ranking is shown in Figure 4.

Step 1. If two values in comprehensive results are comparable, then go to step 2; else go to step 3.

Step 2. The comparable values can be ranked by the lattice structure according to the Figure 1.

Step 3. For the incomparable values are mapped to real number by LR-PVF. For example, suppose $\left(h_{i}, c_{k}\right),\left(h_{j}, c_{l}\right)$ are incomparable, then $\left(h_{i}, c_{k}\right),\left(h_{j}, c_{l}\right)$, and $\left(h_{i}, c_{k}\right) \wedge\left(h_{j}, c_{l}\right)$ or $\left(h_{i}, c_{k}\right) \vee\left(h_{j}, c_{l}\right)$ are mapped to real number according to Eq. (15),

$$
\begin{gathered}
v\left(\left(h_{i}, c_{k}\right)\right)=r_{1}, \\
v\left(\left(h_{j}, c_{l}\right)\right)=r_{2}, \\
v\left(\left(h_{i}, c_{k}\right) \wedge\left(h_{j}, c_{l}\right)\right)=p \text { or } v\left(\left(h_{i}, c_{k}\right) \vee\left(h_{j}, c_{l}\right)\right)=q .
\end{gathered}
$$

Step 4. Linguistic-real distance computing. According to Eqs. (17) and (18), denote the linguistic-real distance between $\left(h_{i}, c_{k}\right)$ and $\left(h_{i}, c_{k}\right) \wedge\left(h_{j}, c_{l}\right)$ as $D c_{1}$, and denote the linguistic-real distance between $\left(h_{j}, c_{l}\right)$ and $\left(h_{i}, c_{k}\right) \wedge\left(h_{j}, c_{l}\right)$ as $D c_{2}$ respectively. Or according to Eqs. (19) and (20), denote the linguistic-real distance between $\left(h_{i}, c_{k}\right)$ and $\left(h_{i}, c_{k}\right) \vee\left(h_{j}, c_{l}\right)$ as $D d_{1}$ and $\left(h_{j}, c_{l}\right)$ and $\left(h_{i}, c_{k}\right) \vee\left(h_{j}, c_{l}\right)$ as $D d_{2}$ respectively.

$$
\begin{aligned}
& D c_{1}=v\left(\left(h_{i}, c_{k}\right)\right)-v\left(\left(h_{i}, c_{k}\right) \wedge\left(h_{j}, c_{l}\right)\right)=r_{1}-p, \\
& D c_{2}=v\left(\left(h_{j}, c_{l}\right)\right)-v\left(\left(h_{i}, c_{k}\right) \wedge\left(h_{j}, c_{l}\right)\right)=r_{2}-p .
\end{aligned}
$$

or

$$
\begin{aligned}
& D d_{1}=v\left(\left(h_{i}, c_{k}\right) \vee\left(h_{j}, c_{l}\right)\right)-v\left(\left(h_{i}, c_{k}\right)\right)=q-r_{1}, \\
& D d_{2}=v\left(\left(h_{i}, c_{k}\right) \vee\left(h_{j}, c_{l}\right)\right)-v\left(\left(h_{j}, c_{l}\right)\right)=q-r_{2} .
\end{aligned}
$$

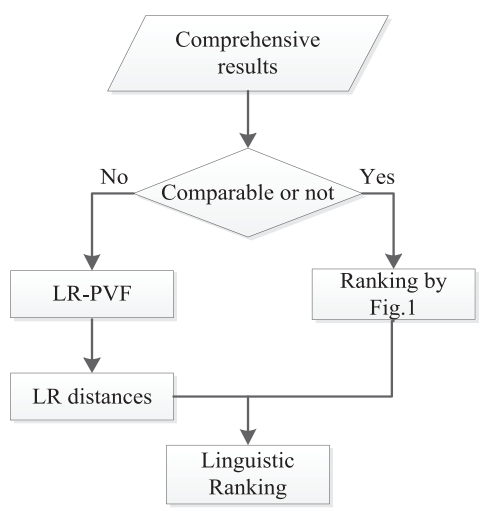

Figure 4 The flowchart of ranking with incomparable results.
Step 5. Incomparable ranking process. If $D c_{1}<D c_{2}$ or $D d_{1}>D d_{2}$, then $\left(h_{i}, c_{k}\right)<\left(h_{j}, c_{l}\right)$.

Example 3. In the teaching evaluation system, when the weight vector is $W_{2}$, teacher $A_{2}, A_{3}$ and teacher $A_{4}$ are incomparable. We show the incomparable ranking process by rank $A_{2}\left(=A_{3}\right)=$ $\left(h_{3}, c_{2}\right)$ and $A_{4}=\left(h_{4}, c_{1}\right)$.

The preference parametersare set as $\alpha=0.2, \beta=0.8$ by experience. It means that the preference degree to the positive side is lower than negative side on 18LV-LIA, then

$$
v\left(\left(h_{i}, c_{k}\right)\right)= \begin{cases}0.8 \cdot(8-i), & k=1, \\ 0.2+0.8 \cdot i, & k=2 .\end{cases}
$$

Step 1. The comparable values has been ranked in the Section 3.

Step 2. Linguistic valuation function computing:

According to Eq. (21),

$$
\begin{gathered}
v\left(\left(h_{3}, c_{2}\right)\right)=2.6, \\
v\left(\left(h_{4}, c_{1}\right)\right)=3.2, \\
v\left(\left(h_{3}, c_{2}\right) \wedge\left(h_{4}, c_{1}\right)\right)=v\left(\left(h_{5}, c_{1}\right)\right)=2.4 \text { or } \\
v\left(\left(h_{3}, c_{2}\right) \vee\left(h_{4}, c_{1}\right)\right)=v\left(\left(h_{4}, c_{2}\right)\right)=3.4 .
\end{gathered}
$$

Step 3. Linguistic-real distance: The linguistic-real distance $D c_{1}$ and $D c_{2}$ are got as follows.

$$
\begin{aligned}
D c_{1} & =d l\left(\left(h_{3}, c_{2}\right),\left(\left(h_{3}, c_{2}\right) \wedge\left(h_{4}, c_{1}\right)\right)\right) \\
& =v\left(\left(h_{3}, c_{2}\right)\right)-v\left(\left(h_{3}, c_{2}\right) \wedge\left(h_{4}, c_{1}\right)\right)=0.2, \\
D c_{2} & =d l\left(\left(h_{4}, c_{1}\right),\left(\left(h_{3}, c_{2}\right) \wedge\left(h_{4}, c_{1}\right)\right)\right) \\
& =v\left(\left(h_{4}, c_{1}\right)\right)-v\left(\left(h_{3}, c_{2}\right) \wedge\left(h_{4}, c_{1}\right)\right)=0.8 .
\end{aligned}
$$

Step 4. Ranking process:

Since $D c_{1}<D c_{2}$, so $\left(h_{3}, c_{2}\right) \ddot{*}\left(h_{4}, c_{1}\right)$.

We also can do that in another way. In step 3, linguistic-real distance between $\left(h_{3}, c_{2}\right)$ and $\left(h_{3}, c_{2}\right) \vee\left(h_{4}, c_{1}\right)$ noted as $D d_{1},\left(h_{4}, c_{1}\right)$ and $\left(h_{3}, c_{2}\right) \vee\left(h_{4}, c_{1}\right)$ noted as $D d_{2}$.

$$
\begin{aligned}
D d_{1} & =d l\left(\left(h_{3}, c_{2}\right),\left(\left(h_{3}, c_{2}\right) \vee\left(h_{4}, c_{1}\right)\right)\right) \\
& =v\left(\left(h_{3}, c_{2}\right) \vee\left(h_{4}, c_{1}\right)\right)-v\left(\left(h_{3}, c_{2}\right)\right)=0.8, \\
D d_{2} & =d l\left(\left(h_{4}, c_{1}\right),\left(\left(h_{3}, c_{2}\right) \vee\left(h_{4}, c_{1}\right)\right)\right) \\
& =v\left(\left(h_{3}, c_{2}\right) \vee\left(h_{4}, c_{1}\right)\right)-v\left(\left(h_{4}, c_{1}\right)\right)=0.2 .
\end{aligned}
$$

It is obvious that $D d_{1}>D d_{2}$, so $\left(h_{3}, c_{2}\right) \stackrel{*}{<}\left(h_{4}, c_{1}\right)$.

From above, the best one in teaching quality is teacher $A_{4}$ if the system highlight the negative evaluations.

When the preference changes, the ranking results would change. Figure 5 shows $D c_{1}$ and $D c_{2}$ relation under different preference parameters.

From Figure 5, $D c_{1}$ and $D c_{2}$ is changing following preference parameters. When $\alpha=\beta, D c_{1}=D c_{2}$; When $\alpha>\beta, D c_{1}<D c_{2}$; When $\beta<\alpha, D c_{1}>D c_{2}$. It shows that the incomparable ranking results can be adjust elastic related to people's preference to positive side and negative side. 


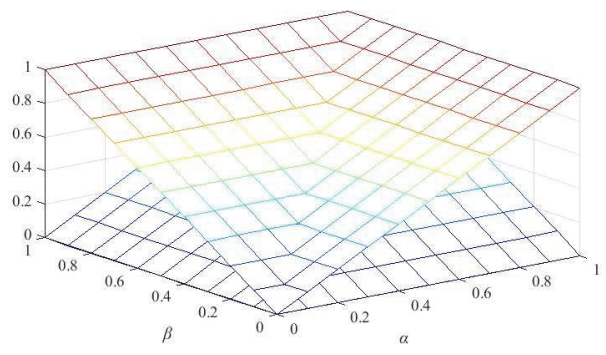

Figure $5 \quad D c_{1}$ and $D c_{2}$ with different preference parameters.

\section{CONCLUSIONS}

LV-LIA can deal with linguistic information by manipulating directly linguistic terms without numerical approximation. We proposed a linguistic approach of decision making with linguistic weight based on LV-LIA to deal with the attribute in different importance degree. The contrast example illustrated the proposed approach is more widely in setting weight and more flexible in linguistic aggregation. The attribute weight can be positive prime terms or negative prime terms which are on a lattice structure rather than a linear construction. The linguistic aggregation function for weighted evaluations comprehensive can be logical operations or arithmetic operations or hybrid ones. It makes the proposed approach more widely applied.

Incomparable linguistic results sometimes exist and are rational. In this paper we defined a PVF named LR-PVF by which the LV-LIA can be mapped to a real set. The distance implied by LV-LIA was used to do further works when these incomparable linguistic results need to be ranked. It is elastic by adjusting the performance parameters setting by individual performance to the positive side and negative side.

The proposed approach can be extended into more fields such as pattern recognition, risk analysis, quality evaluation and so on. The data and the parameters in the example are by experience in this paper. It will lead more convincing conclusion with practical data.

\section{Funding Statement}

This work was supported by the National Natural Science Foundation of P. R. China (Nos. 61772250, 61672127).

\section{REFERENCES}

[1] L.A. Zadeh, Fuzzy logic = computing with words, IEEE Trans. Fuzzy Syst. 4 (1996), 103-111.

[2] L.A. Zadeh, The concept of linguistic variable and application to approximate reasoning, Part I, Part II, Part III, Inf. Sci. 8 (1975), 199-249, 8, 301-357, 9, 43-80.

[3] M. Mizumoto, K. Tanaka, Some properties of fuzzy sets of type 2, Inf. Control. 31 (1976), 312-340.

[4] J.M. Mendel, H. Wu, Type-2 fuzzistics for nonsymmetric interval type-2 fuzzy sets: forward problems, IEEE Trans. Fuzzy Syst. 15 (2007), 916-930.

[5] D. Meng, Z. Pei, On weighted unbalanced linguistic aggregation operators in group decision making, Inf. Sci. 223 (2013), 31-41.
[6] R.M. Rodriguez, L. Martinez, F. Herrera, Hesitant fuzzy linguistic term sets for decision making, IEEE Trans. Fuzzy Syst. 20 (2012), 109-119.

[7] Y.Xu, S.W. Chen, J. Ma, Linguistic truth-valued lattice implication algebra and its properties, in Proceedings CESA'06, Piscataway, 2006, pp. 1413-1418.

[8] Y. Xu, J. Liu, D. Ruan, X.B. Li, Determination of -resolution in lattice-valued first-order logic LF(X), Inf. Sci. 181 (2011), $1836-1862$.

[9] P. Jaya, J.S. Jacob, Type-2 fuzzy multisets and its applications in decision making problems, J. Intell. Fuzzy Syst. 30 (2016), 359-369.

[10] L. Livi, H. Tahayori, A. Rizzi, et al., Classification of type-2 fuzzy sets represented as sequences of vertical slices, IEEE Trans. Fuzzy Syst. 24 (2016), 1022-1034.

[11] J.H. Hu, Y. Zhang, X.H. Chen, et al., Multi-criteria decision making method based on possibility degree of interval type-2 fuzzy number, Knowl. Based Syst. 43 (2013), 21-29.

[12] M. Kilic, I. Kaya, Investment project evaluation by a decision making methodology based on type-2 fuzzy sets, Appl. Soft Comput. 27 (2015), 399-410.

[13] M. Delgado, J.L. Verdegay, M.A. Vila, On aggregation operations of linguistic labels, Int. J. Intell. Syst. 8 (1993), 351-370.

[14] K.S.B. Hadj, B. Amel, T. Moncef, Extended symbolic approximate reasoning based on linguistic modifiers, Knowl. Inf. Syst. 42 (2015), 633-661.

[15] Y.C. Dong, Y.Z. Wu, H.J. Zhang, Multi-granular unbalanced linguistic distribution assessments with interval symbolic proportions, Knowl. Based Syst. 82 (2015), 139-151.

[16] R.M. Rodriguez, L. Martinez, An analysis of symbolic linguistic computing models in decision making, Int. J. Gen. Syst. 42 (2013), 121-136.

[17] F. Herrera, L. Martinez. A 2-tuple fuzzy linguistic representation model for computing with words, IEEE Trans. Fuzzy Syst. 8 (2000), 746-752.

[18] F. Herrera, L. Martinez, A model based on linguistic 2-tuples for dealing with multi-granular hierarchical linguistic contexts in multi-expert decision-making, IEEE Trans. Syst. Man Cybern. Part B Cybern. 31 (2001), 227-234.

[19] Y.C. Dong, C.C. Li, F. Herrera, Connecting the linguistic hierarchy and the numerical scale for the 2-tuple linguistic model and its use to deal with hesitant unbalanced linguistic information, Inf. Sci. 367 (2016), 259-278.

[20] H.C. Liu, Q.L. Lin, J. Wu, Dependent interval 2-tuple linguistic aggregation operators and their application to multiple attribute group decision making, Int. J. Uncertain. Fuzziness Knowl. Based Syst. 22 (2014), 717-735.

[21] D. Bapi, G. Debashree, M. Radko, A model based on linguistic 2-tuples for dealing with heterogeneous relationship among attributes in multi-expert decision making, IEEE Trans. Fuzzy Syst. 23 (2015), 1817-1831.

[22] J. Wang, J.Q. Wang, H.Y. Zhang, Multi-criteria group decisionmaking approach based on 2-tuple linguistic aggregation operators with multi-hesitant fuzzy linguistic information, IEEE Trans. Fuzzy Syst. 18 (2016), 81-97.

[23] X.X. He, Y. Xu, J. Liu, S.W. Chen, On compatibilities of $\alpha$-lock resolution method in linguistic truth-valued lattice-valued logic, Soft Comput. 16 (2012), 699-709.

[24] X.X. He, Y. Xu, J. Liu, S.W. Chen, $\alpha$-Generalized lock resolution method in linguistic truth-valued lattice-valued logic, Int. J. Comput. Intell. Syst. 5 (2012), 1120-1134. 
[25] J. Liu, W.J. Li, S.W. Chen, Y. Xu, An axiomatizable logical foundation for lattice-ordered qualitative linguistic approach for reasoning with words, Inf. Sci. 263 (2014), 110-125.

[26] X.X. He, Y. Xu, J. Liu, S.W. Chen, A unified algorithm for finding k-IESFs in linguistic truth-valued lattice-valued propositional logic, Soft Comput. 18 (2014), 2135-2147.

[27] X.M. Zhong, Y. Xu, J. Liu, S.W. Chen, General form of a-resolution principle for linguistic truth-valued lattice-valued logic, Soft Comput. 16 (2012), 1767-1781.

[28] Y. Liu, V.G. Kaburlasos, A.G. Hatzimichailidis, Y. Xu, Toward a synergy of a lattice implication algebra with fuzzy lattice reasoning-a lattice computing approach, in: G.A. Papakostas, A.G. Hatzimichailidis, V.G. Kaburlasos (Eds.), Handbook of Fuzzy Sets Comparison-Theory, Algorithms and Applications, Science Gate Publishing (SGP), Xanthi, vol. 6, 2016, pp. 23-42.
[29] L. Zou, Y.X. Zhang, X. Liu, Linguistic-valued approximate reasoning with lattice ordered linguistic-valued credibility, Int. J. Comp. Intell. Syst. 8 (2015), 53-61.

[30] S.W. Chen, J. Liu, H. Wang, A linguistic multi-criteria decision making approach based on logical reasoning, Inf. Sci. 28 (2014), 266-276.

[31] V.G. Kaburlasos, FINs: lattice theoretic tools for improving prediction of sugar production from populations of measurements, IEEE Trans. Syst. Man Cybern. Part B Cybern. 34 (2004), 10171030.

[32] L. Zou, X. Liu, D. Ruan, Y. Xu, Linguistic truth-valued intuitionistic fuzzy algebra, J. Mul. Val. Logic Soft Comput. 18 (2012), $445-456$. 


\section{APPENDIX A}

\section{Proof of Theorem 3}

The proof of Theorem 3 is as below.

Proof. There are two conditions should be proved to convince that $v: \mathcal{L}_{V((n+1) \times 2)} \rightarrow R$ is a positive valuation function. For any $\left(h_{i}, c_{k}\right),\left(h_{j}, c_{l}\right) \in \mathcal{L}_{V((n+1) \times 2)}$,

i. $\quad v\left(\left(h_{i}, c_{k}\right) \vee\left(h_{j}, c_{l}\right)\right)+v\left(\left(h_{i}, c_{k}\right) \wedge\left(h_{j}, c_{l}\right)\right)=v\left(\left(h_{i}, c_{k}\right)\right)+$ $v\left(\left(h_{j}, c_{l}\right)\right)$,

ii. If and only if $\left(h_{i}, c_{k}\right)<\left(h_{j}, c_{l}\right)$ implies $v\left(\left(h_{i}, c_{k}\right)\right)<v\left(\left(h_{j}, c_{l}\right)\right)$.

i. The first condition is proved as the following.

To prove $v\left(\left(h_{i}, c_{k}\right) \vee\left(h_{j}, c_{l}\right)\right)+v\left(\left(h_{i}, c_{k}\right) \wedge\left(h_{j}, c_{l}\right)\right)$ $=v\left(\left(h_{i}, c_{k}\right)\right)+v\left(\left(h_{j}, c_{l}\right)\right)$. We formulize the operation " $\vee$ " and " $\wedge$ " are shown in Figure 1.

$$
\begin{aligned}
& \left(h_{i}, c_{k}\right) \vee\left(h_{j}, c_{l}\right)= \begin{cases}\left(h_{i \vee j}, c_{2}\right), & k=l=2, \\
\left(h_{i \wedge j}, c_{1}\right), & k=l=1, \\
\left(h_{i \vee(n-k)}, c_{2}\right), & k=2, l=1 .\end{cases} \\
& \left(h_{i}, c_{k}\right) \wedge\left(h_{j}, c_{l}\right)= \begin{cases}\left(h_{i \wedge j}, c_{2}\right), & k=l=2, \\
\left(h_{i \vee j}, c_{1}\right), & k=l=1, \\
\left(h_{(n-i) \vee j}, c_{1}\right), & k=2, l=1 .\end{cases}
\end{aligned}
$$

Then we'll prove it in three cases according to the operations " $\vee$ " and " $\wedge$ ".

(a) When $j=l=2$, according to Eq. (15),

$$
\begin{aligned}
v\left(\left(h_{i}, c_{k}\right)\right)+v\left(\left(h_{j}, c_{l}\right)\right) & =(\alpha+\beta \times i)+(\alpha+\beta \times j) \\
& =2 \alpha+\beta(i+j) .
\end{aligned}
$$

And

$$
\begin{aligned}
& v\left(\left(h_{i}, c_{k}\right) \vee\left(h_{j}, c_{l}\right)\right)=v\left(\left(h_{i \vee j}, c_{2}\right)\right)=\alpha+\beta \times(i \vee j), \\
& v\left(\left(h_{i}, c_{k}\right) \wedge\left(h_{j}, c_{l}\right)\right)=v\left(\left(h_{i \wedge j}, c_{2}\right)\right)=\alpha+\beta \times(i \wedge j) .
\end{aligned}
$$

Then

$$
\begin{aligned}
& v\left(\left(h_{i}, c_{k}\right) \vee\left(h_{j}, c_{l}\right)\right)+v\left(\left(h_{i}, c_{k}\right) \wedge\left(h_{j}, c_{l}\right)\right) \\
& \quad=2 \alpha+\beta \times((i \vee j)+(i \wedge j))=2 \alpha+\beta(i+j) .
\end{aligned}
$$

Therefore, we get

$$
\begin{aligned}
& v\left(\left(h_{i}, c_{k}\right) \vee\left(h_{j}, c_{l}\right)\right)+v\left(\left(h_{i}, c_{k}\right) \wedge\left(h_{j}, c_{l}\right)\right) \\
& \quad=v\left(\left(h_{i}, c_{k}\right)\right)+v\left(\left(h_{j}, c_{l}\right)\right) .
\end{aligned}
$$

(b) when $j=l=1$, according to Eq. (15),

$$
\begin{aligned}
v\left(\left(h_{i}, c_{k}\right)\right)+v\left(\left(h_{j}, c_{l}\right)\right) & =\beta(n-i)+\beta(n-k) \\
& =\beta(2 n-2-i-k) .
\end{aligned}
$$

And

$$
\begin{aligned}
& v\left(\left(h_{i}, c_{j}\right) \vee\left(h_{k}, c_{l}\right)\right)=v\left(\left(h_{i \wedge k}, c_{1}\right)\right)=\beta(n-(i \wedge k)), \\
& v\left(\left(h_{i}, c_{j}\right) \wedge\left(h_{k}, c_{l}\right)\right)=v\left(\left(h_{i \vee k}, c_{1}\right)\right)=\beta(n-(i \vee k)),
\end{aligned}
$$

Then

$$
\begin{aligned}
& v\left(\left(h_{i}, c_{j}\right) \vee\left(h_{k}, c_{l}\right)\right)+v\left(\left(h_{i}, c_{j}\right) \wedge\left(h_{k}, c_{l}\right)\right) \\
& \quad=\beta(2 n-(i \wedge k)-(i \vee k))=\beta(2 n-i-k) .
\end{aligned}
$$

Therefore,

$$
\begin{aligned}
& v\left(\left(h_{i}, c_{j}\right) \vee\left(h_{k}, c_{l}\right)\right)+v\left(\left(h_{i}, c_{j}\right) \wedge\left(h_{k}, c_{l}\right)\right) \\
& \quad=v\left(\left(h_{i}, c_{k}\right)\right)+v\left(\left(h_{j}, c_{l}\right)\right) .
\end{aligned}
$$

(c) When $j \neq l$, without loss of generality, let $j=2, l=1$,

$$
\begin{aligned}
v\left(\left(h_{i}, c_{k}\right)\right)+v\left(\left(h_{j}, c_{l}\right)\right) & =(\alpha+\beta \times i)+\beta(n-j) \\
& =\alpha+\beta(n+i-j) .
\end{aligned}
$$

And

$$
\begin{aligned}
v\left(\left(h_{i}, c_{k}\right) \vee\left(h_{j}, c_{l}\right)\right) & =v\left(\left(h_{i \vee(n-j)}, c_{2}\right)\right) \\
& =(\alpha+\beta \times(i \vee(n-k))), \\
v\left(\left(h_{i}, c_{k}\right) \wedge\left(h_{j}, c_{l}\right)\right) & =v\left(\left(h_{(n-i) \vee j}, c_{1}\right)\right) \\
& =\beta(n-((n-i) \vee j)) .
\end{aligned}
$$

Then

$$
\begin{aligned}
& v\left(\left(h_{i}, c_{k}\right) \vee\left(h_{j}, c_{l}\right)\right)+v\left(\left(h_{i}, c_{k}\right) \wedge\left(h_{j}, c_{l}\right)\right) \\
& \quad=(\alpha+\beta \times(i \vee(n-j)))+\beta(n-((n-i) \vee j)) .
\end{aligned}
$$

If $i>n-j$, it is easy to know $j>n-i$, so

$$
\begin{aligned}
& v\left(\left(h_{i}, c_{k}\right) \vee\left(h_{j}, c_{l}\right)\right)+v\left(\left(h_{i}, c_{k}\right) \wedge\left(h_{j}, c_{l}\right)\right) \\
& \quad=(\alpha+\beta \times i)+\beta \times(n-j)=\alpha+\beta(n+i-j)
\end{aligned}
$$

If $n+1-k>i$, it is easy to know $n+1-i>k$, so

$$
\begin{aligned}
& v\left(\left(h_{i}, c_{k}\right) \vee\left(h_{j}, c_{l}\right)\right)+v\left(\left(h_{i}, c_{k}\right) \wedge\left(h_{j}, c_{l}\right)\right) \\
& =(\alpha+\beta \times((n-j)))+\beta \times(n-(n-i)) \\
& =\alpha+\beta(n+i-j) .
\end{aligned}
$$

Therefore, we get

$$
\begin{aligned}
& v\left(\left(h_{i}, c_{k}\right) \vee\left(h_{j}, c_{l}\right)\right)+v\left(\left(h_{i}, c_{k}\right) \wedge\left(h_{j}, c_{l}\right)\right) \\
& \quad=v\left(\left(h_{i}, c_{k}\right)\right)+v\left(\left(h_{j}, c_{l}\right)\right) .
\end{aligned}
$$

ii. The second condition is proved as the following. According to

(a) when $k=l=2$, if $\left(h_{i}, c_{k}\right)<\left(h_{j}, c_{l}\right)$, then $i<j$

$$
v\left(\left(h_{i}, c_{k}\right)\right)=\alpha+\beta \times i<\alpha+\beta \times j=v\left(\left(h_{j}, c_{l}\right)\right) .
$$

If $v\left(\left(h_{i}, c_{k}\right)\right)<v\left(\left(h_{j}, c_{l}\right)\right)$, i.e. $\alpha+\beta \times i<\alpha+\beta \times j$, then $i<j$, hence $\left(h_{i}, c_{k}\right)<\left(h_{j}, c_{l}\right)$.

(b) When $k=l=1$, if $\left(h_{i}, c_{k}\right)<\left(h_{j}, c_{l}\right)$, then $i>j$. $v\left(\left(h_{i}, c_{k}\right)\right)=\beta(n-i)<\beta(n-j)=v\left(\left(h_{j}, c_{l}\right)\right)$. If $v\left(\left(\left(h_{i}, c_{k}\right)\right)<v\left(\left(h_{j}, c_{l}\right)\right)\right.$, i.e. $\beta(n-i)<\beta(n-j)$, then $i>j$, hence $\left(h_{i}, c_{k}\right)<\left(h_{j}, c_{l}\right)$.

(c) When $k=1, l=2$, if $\left(h_{i}, c_{k}\right)<\left(h_{j}, c_{l}\right)$, then $i \geq n-j$. $v\left(\left(h_{i}, c_{k}\right)\right)=\beta(n-i) \leq \beta \times j<\alpha+\beta \times j=v\left(\left(h_{j}, c_{l}\right)\right)$. If $v\left(\left(h_{i}, c_{k}\right)\right)<v\left(\left(h_{j}, c_{l}\right)\right)$, that is to say, $\beta(n-i)<\alpha+$ $\beta \times j<\beta(j+1)$ for $\alpha<\beta$, then $n-i<j+1$. Because $n, i, j$ are positive integers, $n-i \leq j$, i.e., $i \geq n-j$. Then $\left(h_{i}, c_{k}\right)<\left(h_{j}, c_{l}\right)$. 